\title{
Outcomes after early and delayed rehabilitation for exacerbation of chronic obstructive pulmonary disease: a nationwide retrospective cohort study in Japan
}

\author{
Hiroki Matsui ${ }^{1 *}$, Taisuke Jo ${ }^{2}$, Kiyohide Fushimi ${ }^{3}$ and Hideo Yasunaga ${ }^{1}$
}

\begin{abstract}
Background: The effectiveness of early pulmonary rehabilitation (PR) for exacerbation of chronic obstructive pulmonary disease (COPD) remains controversial. The present study aimed to compare the outcomes between early and delayed PR for exacerbation of COPD, using a national inpatient database.

Methods: Using the Japanese Diagnosis Procedure Combination database, we examined patients who were transported to hospital for exacerbation of COPD, received PR during hospitalisation, and were discharged to their home. The patients were divided into those who received early PR (defined as PR starting within $48 \mathrm{~h}$ of admission) and those who received delayed PR. The outcomes included 90-day readmission, length of stay (LOS), and activities of daily living (Barthel index $\geq 15$ ) at discharge. Multiple imputation was used for missing data. To assess the associations between early PR and the outcomes, we used risk-adjusted treatment effects and instrumental variable methods.

Results: We identified 12,572 eligible patients, including 8459 patients with delayed PR and 4113 with early PR. In the risk-adjusted treatment effect models, the early PR group had lower proportion of 90-day readmission (risk difference, $-3.4 \% ; 95 \% \mathrm{Cl},-5.7 \%$ to $-1.5 \%)$ and shorter LOS ( -9.8 days; $95 \% \mathrm{Cl},-10.8$ days to -8.7 days) than the delayed PR group. There was no significant difference in activities of daily living at discharge between the two groups. The instrumental variable analyses showed similar results.
\end{abstract}

Conclusions: In this national database study, early PR was associated with reduced 90-day readmission and shortened LOS in patients with exacerbation of COPD.

Keywords: COPD exacerbation, Pulmonary rehabilitation, Clinical epidemiology

\section{Background}

Exacerbation of chronic obstructive pulmonary disease (COPD) can cause frequent unplanned hospitalisations, which potentially result in death and functional disability [1-3].

The effects of early pulmonary rehabilitation (PR) for unstable COPD patients remain controversial. Several

\footnotetext{
* Correspondence: ptmatsui-tky@umin.ac.jp

${ }^{1}$ Department of Clinical Epidemiology and Health Economics, School of

Public Health, The University of Tokyo, 7-3-1 Hongo, Bunkyo-ku, Tokyo

113-0033, Japan

Full list of author information is available at the end of the article
}

previous small-size randomised controlled trials (RCT) showed that early PR reduced readmission and all-cause mortality, and improved patient exercise capability and quality of life [4]. However, recent RCTs produced conflicting results $[5,6]$.

Although clinical RCTs remain the gold standard for assessing the efficacy of healthcare services, they can only measure the "efficacy" of an intervention under ideal and controlled circumstances. Therefore, the "effectiveness" of early PR for unstable COPD patients remains unclear in routine clinical settings with more heterogeneous populations and less-standardized treatment protocols. 
Using a national inpatient database in Japan, the present study aimed to estimate the real-world effectiveness of early PR for exacerbation of COPD compared with delayed PR.

\section{Methods}

Data source

For the present retrospective cohort study, we used the Diagnosis Procedure Combination database, a Japanese national inpatient database. The database contains administrative claims data and discharge abstracts, and has information on dates and doses of drugs used and daily records of examinations and procedures (including rehabilitation). The database includes the following data: type of admission (planned or unplanned); ambulance service use; and patients' main diagnoses, comorbidities at admission, and complications after admission. All diagnoses are coded with International Classification of Diseases and $\mathrm{Re}$ lated Health Problems 10th revision (ICD-10) codes. A previous validation study showed good sensitivity and excellent specificity of diagnoses in the database [7]. The database also contains the following detailed patient information: age; sex; body height and weight; smoking index; severity of dyspnoea at admission, based on the Hugh-Jones dyspnoea scale (grades I to V) [8]; level of consciousness at admission, based on the Japan Coma Scale (JCS) [9]; and activities of daily living (ADL) at admission and discharge, based on the Barthel index (0-20) [10].

\section{Patient selection}

We retrospectively collected patients who were admitted to hospitals with a diagnosis of COPD (ICD-10 codes: $\mathrm{J} 41-\mathrm{J} 44$ ) as the main diagnosis or diagnosis at admission and discharged between 1 July 2010 and 31 December 2013. The readmission records of the identified patients were followed from 1 July 2010 to 31 March 2014. We included patients who met all of the following criteria: (i) primary diagnosis of COPD at admission; (ii) unplanned admission by ambulance service use; (iii) receipt of PR during hospitalisation; (iv) and discharge to their home. For patients with two or more hospitalisations, we only included data for the initial hospitalisation. We excluded patients who were hospitalised for more than 180 days. We compared the basic characteristics of the included and excluded patients.

\section{Early PR}

We defined early PR as any type and intensity of PR started within $48 \mathrm{~h}$ of admission. Delayed PR was defined as any type of PR started after $48 \mathrm{~h}$ of admission. In Japan, rehabilitation is reimbursed by public health insurance. In general, geriatric PR includes physical therapy that mainly focuses on improving physical function, i.e., PR that provides early ambulation and adaptive or assistive exercises to assist patients in standing, balancing, and walking better [11].

\section{Outcomes}

The primary outcome was readmission within 90 days of discharge. We used length of stay (LOS) as a secondary outcome variable. Because LOS had a skewed distribution, we used the log-transformed LOS. A previous study showed that a Barthel Index score of $<15$ was a strong predictor of in-hospital mortality in patients with COPD [12]. Therefore, the present study used Barthel Index $\geq$ 15 at discharge as another secondary outcome.

\section{Covariates}

We compared the following covariates between the early and delayed PR groups: age; sex; Hugh-Jones dyspnoea scale; JCS on admission; Charlson comorbidity index calculated by recorded ICD-10 codes [13]; ADL at admission; smoking index (defined as number of cigarettes smoked per day multiplied by number of years smoked); use of corticosteroid on day of admission (converted to equivalent dose of prednisolone [14]); use of mechanical ventilation on day of admission; use of oxygen on day of admission; intensive care unit admission; and all-cause pre-admission history within 180 days prior to admission. According to a previous study [15], we divided body mass index into the following five categories: <18.5, 18.5-22.9, 23.0-24.9, 25.029.9 , and $\geq 30 \mathrm{~kg} / \mathrm{m}^{2}$. Because a previous study showed that annual case-volume of COPD patients was associated with outcomes [16], we included annual hospital volume of COPD admissions in the analysis. We also included population density of patient neighbourhood area and distance between patient residence and the hospital as proxies for the local organization of health care provision. To understand the details of the rehabilitation programme, we summarized data on total PR sessions (hours) and PR duration (days) for each group.

A standardized difference between the early and delayed PR groups was calculated for all covariates, with values of $>10 \%$ defined as out of balance $[17,18]$.

\section{Statistical analysis}

\section{Risk-adjusted treatment effect}

We estimated the risk-adjusted treatment effect of early PR as the difference between the risk-adjusted outcomes of each treatment arm [19, 20] (known as predictive margins, model-adjusted means, or g-formula). For this 
estimation, we conducted the following steps: (i) construction of a prediction model for each outcome including all covariates (except total PR sessions and duration of PR) and early PR as the predictors; (ii) setting of the PR status for each arm; (iii) calculation of predicted probabilities or values with the distribution of the covariates in our study population; and (iv) calculation of differences in the predicted probabilities (or values) between the arms. We estimated standard errors with the cluster bootstrap method [21].

\section{Instrumental variable analysis}

Because the risk-adjusted treatment effects could be biased by unmeasured confounders, we conducted instrumental variable analyses. In general, instrumental variables meet the following criteria: (i) not associated with patient background characteristics; (ii) associated with treatment selection; and (iii) not directly associated with outcomes [22, 23]. For this study, we used the differential distance (DD) [24, 25] as an instrumental variable. DD was defined as the difference between the distance from patient home to nearest hospital (d1) and the distance from patient home to nearest hospital conducting early PR for half of COPD patients (d2); that is, DD equals $\mathrm{d} 1-\mathrm{d} 2$.
We divided DD into two categories: 0 and $>0$. The adjusted treatment effect was estimated by the ordinary least square (OLS) model with all covariates and the two-stage least square (2SLS) model with all covariates and $\mathrm{DD}$. The validity of the instrumental variable was tested by F-statistics and the Hausman specification test. The null hypothesis for the Fstatistics was that the instrumental variable was not associated with treatment selection. We investigated whether the instrumental variable met the above criterion (ii). In the present study, the null hypothesis for the Hausman test was that early PR was not endogenous. When the null hypothesis was rejected, early PR was regarded as endogenous, and we adopted the results of the 2SLS model. When the null hypothesis was not rejected, early PR was not regarded as endogenous, and we adopted the results of the OLS model because the variance of the instrumental variable estimator is generally larger than that of the OLS estimator [20].

\section{Multiple imputation}

We performed multiple imputation for missing data on several variables, because complete-case analyses (excluding all patients with missing data) can lead to biased results.

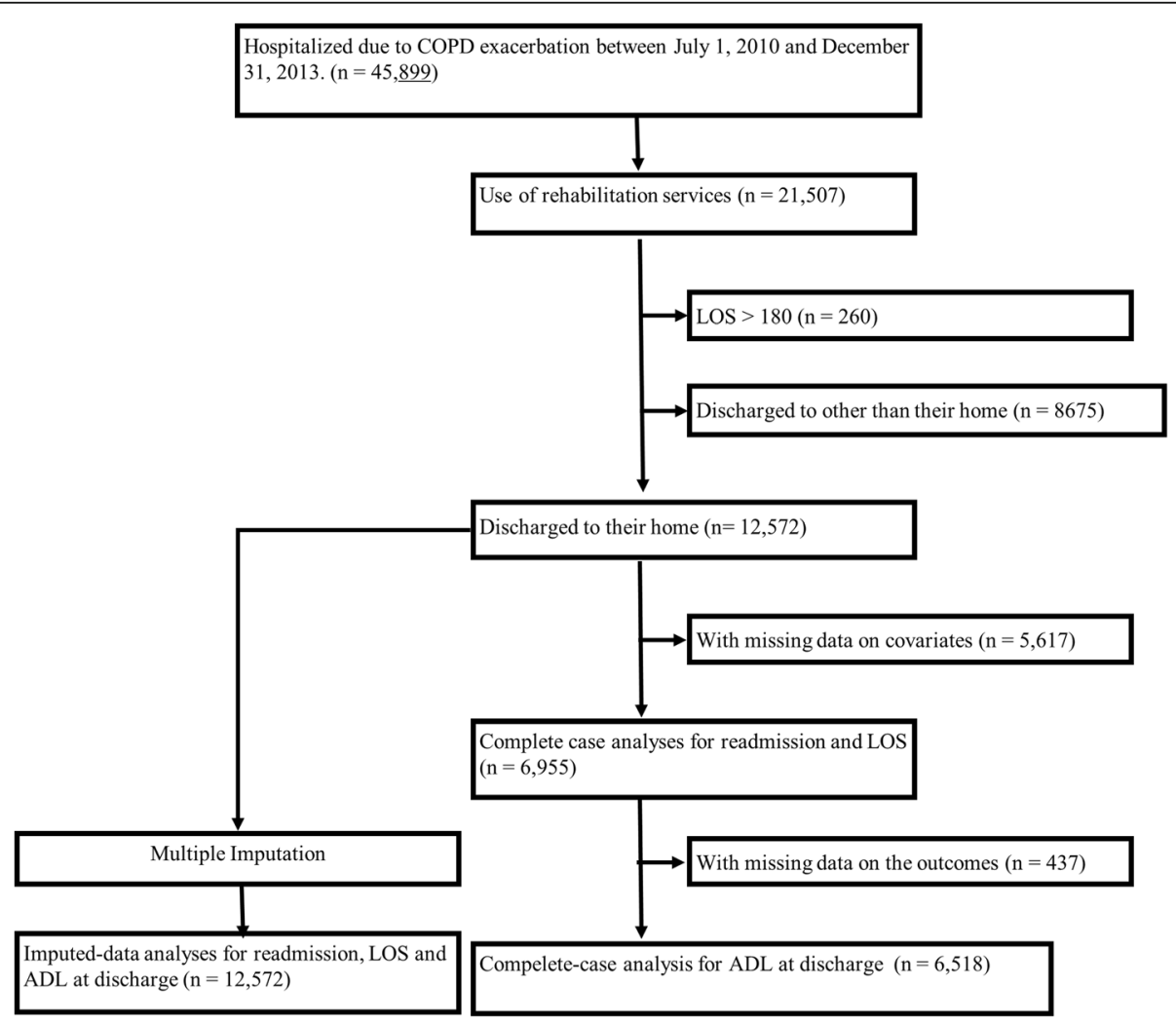

Fig. 1 Patient selection 
Table 1 Patient baseline characteristics by early pulmonary rehabilitation and differential distance

\begin{tabular}{|c|c|c|c|}
\hline & $\begin{array}{l}\text { Delayed pulmonary } \\
\text { rehabilitation }\end{array}$ & $\begin{array}{l}\text { Early pulmonary } \\
\text { rehabilitation }\end{array}$ & $\begin{array}{l}\text { Standardized } \\
\text { difference (\%) }\end{array}$ \\
\hline & $(n=8459)$ & $(n=4113)$ & \\
\hline Age $(y)$, mean (SD) & $77.9(9.5)$ & $79.4(9.3)$ & 15.9 \\
\hline Sex (female), n (\%) & $1646(19.5)$ & 709 (17.2) & 5.7 \\
\hline $\begin{array}{l}\text { Pre-admission } \\
\text { within } 180 \text { days, } \\
n(\%)\end{array}$ & $1951(23.1)$ & $902(21.9)$ & 2.7 \\
\hline $\begin{array}{l}\text { Japan Coma Scale, } \\
\text { n (\%) }\end{array}$ & & & 4.5 \\
\hline Alert & $6415(75.8)$ & $3070(74.6)$ & \\
\hline Dull & $1453(17.2)$ & $745(18.1)$ & \\
\hline Somnolence & $339(4.0)$ & $190(4.6)$ & \\
\hline Coma & $252(3.0)$ & $108(2.6)$ & \\
\hline $\begin{array}{l}\text { Body mass index, } \\
n(\%)\end{array}$ & & & 4.1 \\
\hline$<18.5$ & $2896(34.2)$ & $1476(35.9)$ & \\
\hline $18.5-22.9$ & $2817(33.3)$ & $1362(33.1)$ & \\
\hline $23.0-24.9$ & $701(8.3)$ & $340(8.3)$ & \\
\hline $25.0-29.9$ & $560(6.6)$ & $257(6.2)$ & \\
\hline$\geq 30$ & $115(1.4)$ & $55(1.3)$ & \\
\hline Missing & $1370(16.2)$ & $623(15.1)$ & \\
\hline $\begin{array}{l}\text { Smoking index, } \\
\text { mean (SD) }\end{array}$ & 701 (1420) & $758(1857)$ & 3.4 \\
\hline $\begin{array}{l}\text { Barthel index, } \\
n(\%)\end{array}$ & & & 4.8 \\
\hline 0 & $2935(34.7)$ & $1400(34.0)$ & \\
\hline $5-9$ & $962(11.4)$ & $460(11.2)$ & \\
\hline $10-14$ & $1068(12.6)$ & $580(14.1)$ & \\
\hline $15-19$ & $488(5.8)$ & $253(6.2)$ & \\
\hline 20 & $1209(14.3)$ & $566(13.8)$ & \\
\hline Missing & $1797(21.2)$ & $854(20.8)$ & \\
\hline $\begin{array}{l}\text { Hugh-Jones dyspnoea } \\
\text { scale score, } n(\%)\end{array}$ & & & 16.2 \\
\hline 0 & $1212(14.3)$ & $706(17.2)$ & \\
\hline 1 & $310(3.7)$ & $203(4.9)$ & \\
\hline 2 & $628(7.4)$ & $381(9.3)$ & \\
\hline 3 & 787 (9.3) & $392(9.5)$ & \\
\hline 4 & $1886(22.3)$ & $937(22.8)$ & \\
\hline 5 & $3044(36.0)$ & $1287(31.3)$ & \\
\hline Missing & $592(7.0)$ & $207(5.0)$ & \\
\hline $\begin{array}{l}\text { Charlson comorbidity } \\
\text { index, } n(\%)\end{array}$ & & & 7.5 \\
\hline $0-1$ & $5202(61.5)$ & $2677(65.1)$ & \\
\hline $2-3$ & $2839(33.6)$ & $1247(30.3)$ & \\
\hline$\geq 4$ & $418(4.9)$ & 189 (4.6) & \\
\hline $\begin{array}{l}\text { Intensive care unit } \\
\text { admission, } n(\%)\end{array}$ & $694(8.2)$ & $398(9.7)$ & 5.2 \\
\hline
\end{tabular}

Table 1 Patient baseline characteristics by early pulmonary rehabilitation and differential distance (Continued)

\begin{tabular}{|c|c|c|c|}
\hline $\begin{array}{l}\text { Oxygen intake at } \\
\text { admission, } n(\%)\end{array}$ & $5895(69.7)$ & $2904(70.6)$ & 2 \\
\hline $\begin{array}{l}\text { Intubation at } \\
\text { admission, } n \text { (\%) }\end{array}$ & $364(4.3)$ & $116(2.8)$ & 8 \\
\hline $\begin{array}{l}\text { Steroid dose (mg), } \\
\text { mean (SD) }\end{array}$ & $222(653)$ & $188(549)$ & 5.6 \\
\hline $\begin{array}{l}\text { Hospital volume, } \\
\text { mean (SD) }\end{array}$ & 215 (132) & $233(131)$ & 13.9 \\
\hline \multicolumn{4}{|l|}{$\begin{array}{l}\text { Population density of } \\
\text { patient living area } \\
\text { (persons/km²), } n(\%)\end{array}$} \\
\hline$<250$ & $1281(15.1)$ & $632(15.4)$ & 1.2 \\
\hline$\geq 250$ & $7133(84.4)$ & $3462(84.9)$ & \\
\hline Missing & $45(0.5)$ & $19(0.5)$ & \\
\hline $\begin{array}{l}\text { Distance between } \\
\text { patient residence and } \\
\text { hospital (km), } \\
\text { mean (SD) }\end{array}$ & $6.8(20.8)$ & 7.7 (34.4) & 3.2 \\
\hline $\begin{array}{l}\text { Differential distance, } \\
n(\%)\end{array}$ & & & 31.5 \\
\hline $0 \mathrm{~km}$ & $3782(44.7)$ & $1226(29.8)$ & \\
\hline$>0 \mathrm{~km}$ & $4592(44.3)$ & $2554(69.4)$ & \\
\hline Missing & $85(1.0)$ & $33(0.8)$ & \\
\hline $\begin{array}{l}\text { Total pulmonary } \\
\text { rehabilitation session } \\
\text { (hours), mean (SD) }\end{array}$ & $7.6(11.9)$ & $8.5(12.3)$ & 7.4 \\
\hline $\begin{array}{l}\text { Duration of } \\
\text { pulmonary } \\
\text { rehabilitation } \\
\text { (days), mean (SD) }\end{array}$ & $19.2(21.5)$ & $17.4(18.5)$ & 9.0 \\
\hline
\end{tabular}

We created 50 multiple imputed datasets by chained equations with the mice package of the R Software [26]. All the covariates (except total PR sessions and duration of PR) and outcome variables were included in the data imputation process. We combined all the results and variances based on Rubin's Rule [27]. The $P$-value in each imputed dataset was combined by z-transformation [28]. We also performed complete-case analyses for comparison.

\section{Results}

Among all of the patients hospitalized owing to COPD exacerbation during the study period $(n=45,899)$, we excluded those who did not receive rehabilitation, those with LOS $>180$ days, and those who were discharged to a place other than home. Finally, we identified 12,572 eligible patients during the study period. After exclusion of patients with missing data, there were 6955 patients (Fig. 1).

Appendix 1 Table 5 shows the difference between the included and excluded patients. The excluded patients 
were more likely to have severe consciousness disorders, a lower BMI, severe physical dependence, a lower Barthel index and a lower Hugh-Jones dyspnoea scale score.

Table 1 presents the characteristics of the eligible patients in the early PR group $(n=8459)$ and delayed PR group $(n=4113)$. The patients in the early PR group were significantly older, had lower Hugh-Jones dyspnoea scale scores, and were more likely to be treated in hospitals with larger annual hospital volumes of COPD patients than those in the delayed PR group. The average number of total PR sessions was slightly higher and the duration of PR was slightly shorter in the early PR group, but the standardized differences were $<10 \%$, indicating a well-balanced distribution between the groups.

Appendix 2 Table 6 shows the patient characteristics in the groups with DD of $0 \mathrm{~km}$ or $>0 \mathrm{~km}$. The patient characteristics were well-balanced with standardized differences of $<10$.

Table 2 shows the crude outcomes in the delayed and early PR groups.

Table 3 shows the risk-adjusted treatment effects of early PR on the outcomes. Compared with the delayed PR group, the early PR group had lower 90day readmission (risk difference, $-2.1 \%$; $95 \%$ confidence interval $(\mathrm{CI}),-3.7 \%$ to $-0.5 \%)$ and shorter LOS (difference in LOS, -9.8 days; 95\% CI, -10.7 days to -8.8 days) with adjustment for patient characteristics. There was no significant difference in the proportions of Barthel index $\geq 15$ at discharge between the early and delayed PR groups (risk difference, -0.5\%; 95\% $\mathrm{CI},-2.2 \%$ to $1.1 \%)$.

Table 4 shows the adjusted coefficient estimators of each outcome for early PR in the OLS and 2SLS models. The partial F-statistics from the first-stage regression for each model indicated that DD had sufficient strength for predicting early PR. Early PR was significantly associated with 90-day readmission (coefficient $=-0.021 ; 95 \% \mathrm{CI},-0.036$ to $-0.005 ; P=0.009$ )

Table 2 Crude outcomes in the delayed and early pulmonary rehabilitation groups

\begin{tabular}{llll}
\hline & $\begin{array}{l}\text { Delayed pulmonary } \\
\text { rehabilitation } \\
(n=8459)\end{array}$ & $\begin{array}{l}\text { Early pulmonary } \\
\text { rehabilitation } \\
(n=4113)\end{array}$ & P-value \\
\hline $\begin{array}{l}\text { 90-day readmission, } \\
n(\%)\end{array}$ & $1843(21.8)$ & $809(19.7)$ & 0.007 \\
$\begin{array}{l}\text { Barthel index } \geq 15 \text { at } \\
\text { discharge, } n(\%)\end{array}$ & $4193(49.6)$ & $2027(49.3)$ & 0.776 \\
$\begin{array}{l}\text { Length of stay, mean } \\
(S D)\end{array}$ & $30.4(24.6)$ & $20.3(18.5)$ & $<0.001$ \\
\hline
\end{tabular}

SD standard deviation
Table 3 Risk-adjusted treatment effects of early pulmonary rehabilitation on the outcomes

\begin{tabular}{llc}
\hline & $\begin{array}{l}\text { Risk-adjusted treatment effect } \\
\text { (95\% confidence interval) }\end{array}$ & P-value $^{\text {(95\%) }}$ \\
\hline 90-day readmission (\%) & $-2.1(-3.7,-0.5)$ & 0.009 \\
$\begin{array}{l}\text { Barthel index } \geq 15 \text { at } \\
\text { discharge (\%) }\end{array}$ & $-0.5(-2.2,1.1)$ & 0.504 \\
Length of stay (days) & $-9.8(-10.7,-8.8)$ & $<0.001$ \\
\hline
\end{tabular}

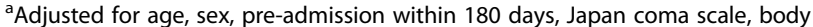
mass index, smoking index, Barthel index, Hugh-Jones dyspnoea scale score, Charlson comorbidity index, intensive care unit admission, steroid dose, hospital volume, population density of patient living area, and distance between patient residence and hospital

in the OLS model, but not in the 2SLS model. The Hausman specification test did not reject the null hypothesis that early PR was exogenous, and we adopted the results of the OLS model. Early PR was significantly associated with log-transformed LOS in both the OLS model (coefficient $=-0.424 ; 95 \% \mathrm{CI}$, -0.463 to $-0.386 ; P<0.001$ ) and 2 SLS model (coefficient $=-0.934 ; 95 \% \mathrm{CI},-1.156$ to $-0.712 ; P<0.001)$. The Hausman specification test rejected the null hypothesis that early PR was exogenous, and we adopted the results of the 2SLS model. Early PR was not significantly associated with ADL at discharge in both the OLS model (coefficient $=-0.009 ; 95 \% \mathrm{CI}$, -0.025 to $0.007 ; P=0.264$ ) and 2SLS model (coefficient $=0.059 ; 95 \% \mathrm{CI},-0.057$ to $0.174 ; P=0.3188)$. The Hausman specification test did not reject the null hypothesis that early PR was exogenous, and we adopted the results of the OLS model.

The results of the complete-case analyses are shown in Appendix 3 Tables 7 and 8 . These results were similar to those in the imputed analyses.

\section{Discussion}

In this national database study, we showed that early PR was associated with lower proportion of 90-day readmission and shorter LOS in patients with exacerbation of COPD. There was no significant difference in the proportions of Barthel index $\geq 15$ between the early PR and delayed PR groups. Our instrumental variable analyses showed that early $P R$ was significantly associated with reduced 90-day readmission and shortened LOS, but not significantly associated with ADL at discharge.

Because our dataset has several missing values, we conducted multiple imputation analyses. Although our analyses hypothesised the missing at random assumption, our complete-case analyses had similar results to the imputed analyses. This indicates the robustness of our analyses. 
Table 4 Ordinary least square and two-stage least square estimates of the outcomes with multiple imputation

\begin{tabular}{|c|c|c|c|c|c|c|}
\hline & \multicolumn{2}{|l|}{ 90-day readmission } & \multicolumn{2}{|c|}{ Barthel index at discharge } & \multicolumn{2}{|c|}{ Log-transformed length of stay } \\
\hline & Coefficient $(95 \% \mathrm{Cl})$ & $P$-value & Coefficient $(95 \% \mathrm{Cl})$ & $P$-value & Coefficient $(95 \% \mathrm{Cl})$ & $P$-value \\
\hline Ordinary least square & $-0.021(-0.036,-0.005)$ & 0.0092 & $-0.009(-0.025,0.007)$ & 0.2644 & $-0.424(-0.463,-0.386)$ & $<0.0001$ \\
\hline Two-stage least square & $-0.053(-0.159,0.053)$ & 0.3269 & $0.059(-0.057,0.174)$ & 0.3188 & $-0.934(-1.156,-0.712)$ & $<0.0001$ \\
\hline F statistics & 247.8 & $<0.0001$ & 247.8 & $<0.0001$ & 247.8 & $<0.0001$ \\
\hline Hausman specification test & & 0.559 & & 0.217 & & $<0.0001$ \\
\hline
\end{tabular}

Cl confidence interval

Previous small-size RCTs showed that early PR improved patient exercise capacity measured by the 6-min walking test $[4,29]$ and readmission rate $[4,30]$. However, recent large RCTs did not show significant improvement of readmission rate $[5,6]$,, but did find escalation of the 1-year mortality rate [6]. These disparities between the studies can be explained by the following two aspects: (i) early PR did not have any effect because of short LOS and training duration and (ii) some other factors (e.g. outpatient PR) could have confounded or mediated between the early and delayed PR groups [31]. Our findings showed that early PR was associated with shorter LOS and lower proportion of 90-day readmission after discharge, possibly because the average LOS in Japan is generally longer than those in other developed nations. However, the effect size on 90-day readmission (about 2\%) was relatively smaller than that in a previous RCT [6] and expected in the sample size calculation (15\%). These findings suggest that the sample sizes in the previous RCTs were too small to have sufficient statistical power for estimating the efficacy of early PR.

As expected, early PR was associated with shorter LOS and lower 90-day readmission rate without worsened ADL status at discharge. Prolonged hospitalisation can reduce patient exercise capacity and may lead to a high probability of readmission [1]. Our results showed that early PR could prevent such adverse effects of prolonged hospitalisation.

Our results indicate that early PR can reduce LOS and readmission rate. Short LOS can improve patient quality of life and reduce hospitalisation costs. A previous study showed that readmission was one of the prognostic factors for COPD [1]. Although the American Thoracic Society recommended early PR for unstable COPD patients, this recommendation was based on an old smallsize RCT [2]. Our findings provide new evidence for early PR in unstable COPD patients. Meanwhile, although early PR reduced 90-day readmission, the effect size was smaller than that in a previous RCT and expected in the sample size calculation [6]. Other factors may affect the readmission rate, such as post-discharge outpatient rehabilitation [32].
The population excluded from our study had more severe consciousness disorders, lower BMIs, and more severe physical dependence. The excluded population included those who did not receive rehabilitation and those who were discharged to a place other than home, and many of these people may have been bedridden.

The present study has some strengths. First, we used a large nationwide inpatient database. Patients with exacerbation of COPD who want to participate in randomised rehabilitation trials are not common in daily clinical settings [4]. A previous RCT could not recruit a sufficient population to detect the effects of early PR [6]. Second, we used instrumental variable and missing value imputation analyses to adjust unmeasured confounders for treatment selection and bias from missing values. Third, we used real-world data from a nationwide inpatient database. The present study verified the overall effectiveness of early rehabilitation compared with non-early rehabilitation for patients with acute exacerbation of COPD in a nationwide, realworld clinical setting.

There are also some limitations to the present study. First, our data did not contain post-discharge long-term outcomes. Therefore, we cannot completely detect post-discharge readmission and deaths. Second, we excluded patients who did not receive PR. This may be limit the generalisability of our study. Third, because of data limitations, we could not analyse the details of the PR programmes. The standardized differences in total PR sessions and duration of PR between the early and delayed groups were $<10 \%$. Fourth, the Barthel index, one of our secondary outcomes, may not be the most appropriate measure to evaluate the effect of PR. However, the database did not include other short-term outcomes [33].

\section{Conclusion}

In summary, early PR was associated with reduced 90-day readmission and shortened LOS without worsened ADL in patients with exacerbation of COPD. These findings suggest that early PR should be conducted in patients with exacerbation of COPD. 


\section{Appendices}

\section{Appendix 1}

Table 5 Patient characteristics in the groups included into or excluded from study

\begin{tabular}{|c|c|c|c|}
\hline & Excluded & Included & Standardized difference (\%) \\
\hline & $n=33327$ & $n=12572$ & \\
\hline Age (years), mean (sd) & $78.3(10.7)$ & $78.4(9.5)$ & 1.0 \\
\hline Sex (female), $n(\%)$ & $6415(19.2)$ & $2355(18.7)$ & 1.3 \\
\hline Pre-admission within 180 day, $n$ (\%) & $7997(24.0)$ & $2853(22.7)$ & 3.1 \\
\hline Japan Coma Scale, $n$ (\%) & & & 20.0 \\
\hline Alert & $22972(68.9)$ & $9485(75.4)$ & \\
\hline Dull & $6234(18.7)$ & $2198(17.5)$ & \\
\hline Somnolence & $2006(6.0)$ & $529(4.2)$ & \\
\hline Coma & $2114(6.3)$ & $360(2.9)$ & \\
\hline Missing & $1(0.0)$ & $0(0.0)$ & \\
\hline Body mass index, $n(\%)$ & & & 13.1 \\
\hline$<18.5$ & $11733(35.2)$ & $4372(34.8)$ & \\
\hline $18.5-22.9$ & $10081(30.2)$ & $4179(33.2)$ & \\
\hline $23.0-24.9$ & $2440(7.3)$ & $1041(8.3)$ & \\
\hline $25.0-29.9$ & $1926(5.8)$ & $817(6.5)$ & \\
\hline$\geq 30$ & $349(1.0)$ & $170(1.4)$ & \\
\hline Missing & $6798(20.4)$ & $1993(15.9)$ & \\
\hline Smoking index, mean (sd) & $4218(596790)$ & $719(1577)$ & 0.8 \\
\hline Barthel index, $n(\%)$ & & & 15.5 \\
\hline 0 & $13601(40.8)$ & $4335(34.5)$ & \\
\hline $5-9$ & $2928(8.8)$ & $1422(11.3)$ & \\
\hline $10-14$ & $3565(10.7)$ & $1648(13.1)$ & \\
\hline $15-19$ & $1882(5.6)$ & $741(5.9)$ & \\
\hline 20 & $4910(14.7)$ & $1775(14.1)$ & \\
\hline Missing & $6441(19.3)$ & $2651(21.1)$ & \\
\hline Hugh-Jones dyspnoea scale score, n (\%) & & & 19.6 \\
\hline 0 & $7076(21.2)$ & $1918(15.3)$ & \\
\hline 1 & $1494(4.5)$ & $513(4.1)$ & \\
\hline 2 & $2412(7.2)$ & $1009(8.0)$ & \\
\hline 3 & $2775(8.3)$ & $1179(9.4)$ & \\
\hline 4 & $5624(16.9)$ & $2823(22.5)$ & \\
\hline 5 & $11574(34.7)$ & $4331(34.4)$ & \\
\hline Missing & $2372(7.1)$ & $799(6.4)$ & \\
\hline Charlson comorbidity index, $n(\%)$ & & & 6.8 \\
\hline $0-1$ & $20712(62.1)$ & $7879(62.7)$ & \\
\hline $2-3$ & $10494(31.5)$ & $4086(32.5)$ & \\
\hline$\geq 4$ & $2121(6.4)$ & $607(4.8)$ & \\
\hline Intensive care unit admission, $n(\%)$ & $2093(6.3)$ & $1088(8.7)$ & 9.2 \\
\hline Oxygen intake at admission, $n$ (\%) & $22151(66.5)$ & $8787(69.9)$ & 7.4 \\
\hline Intubation at admission, $n$ (\%) & $1547(4.6)$ & $478(3.8)$ & 4.2 \\
\hline Steroid dose (mg), mean (sd) & 180.6 (611.3) & $210.6(620.9)$ & 4.9 \\
\hline
\end{tabular}


Table 5 Patient characteristics in the groups included into or excluded from study (Continued)

\begin{tabular}{|c|c|c|c|}
\hline Hospital volume, mean (sd) & $209.4(139.4)$ & $221.1(131.9)$ & 8.6 \\
\hline $\begin{array}{l}\text { Population density of patient living } \\
\text { area } \leq 249 \text { persons } / \mathrm{km}^{2}, n(\%)\end{array}$ & $27697(83.1)$ & $10595(84.3)$ & 3.2 \\
\hline Missing & $169(0.5)$ & $64(0.5)$ & \\
\hline $\begin{array}{l}\text { Distance between patient residence } \\
\text { and hospital }(\mathrm{km}) \text {, mean }(\mathrm{SD})\end{array}$ & $6.0(19.6)$ & $7.1(26.0)$ & 4.6 \\
\hline
\end{tabular}

\section{Appendix 2}

Table 6 Patient characteristics in the groups with differential distance $=0 \mathrm{~km}$ or $>0 \mathrm{~km}$

\begin{tabular}{|c|c|c|c|}
\hline & Differential distance $=0$ & Differential distance $>0$ & Standardized difference (\%) \\
\hline & $n=7446$ & $n=5008$ & \\
\hline Age (years), mean (sd) & $78.7(9.4)$ & $78.1(9.6)$ & 6.6 \\
\hline Sex (female), $n(\%)$ & $1357(18.2)$ & $975(19.5)$ & 3.2 \\
\hline Pre-admission within 180 day, $n$ (\%) & 1695 (22.8) & $1120(22.4)$ & 1 \\
\hline Japan Coma Scale, n (\%) & & & 4.1 \\
\hline Alert & $5604(75.3)$ & $3784(75.6)$ & \\
\hline Dull & $1299(17.4)$ & $882(17.6)$ & \\
\hline Somnolence & $337(4.5)$ & $189(3.8)$ & \\
\hline Coma & $206(2.8)$ & $153(3.1)$ & \\
\hline Body mass index, $n(\%)$ & & & 7.6 \\
\hline$<18.5$ & $2644(35.5)$ & $1684(33.6)$ & \\
\hline $18.5-22.9$ & $2431(32.6)$ & $1710(34.1)$ & \\
\hline $23.0-24.9$ & $648(8.7)$ & $382(7.6)$ & \\
\hline $25.0-29.9$ & $493(6.6)$ & $321(6.4)$ & \\
\hline$\geq 30$ & $87(1.2)$ & $83(1.7)$ & \\
\hline Missing & $1143(15.4)$ & $828(16.5)$ & \\
\hline Smoking index, mean (sd) & $713(1472)$ & 728 (1735) & 0.9 \\
\hline Barthel index, $n$ (\%) & & & 5.1 \\
\hline 0 & $2556(34.3)$ & $1743(34.8)$ & \\
\hline $5-9$ & $858(11.5)$ & $549(11.0)$ & \\
\hline $10-14$ & $1001(13.4)$ & $626(12.5)$ & \\
\hline $15-19$ & $440(5.9)$ & $298(6.0)$ & \\
\hline 20 & $1010(13.6)$ & $751(15.0)$ & \\
\hline Missing & $1581(21.2)$ & $1041(20.8)$ & \\
\hline Hugh-Jones dyspnoea scale score, $n$ (\%) & & & 9.4 \\
\hline 0 & $1182(15.9)$ & $720(14.4)$ & \\
\hline 1 & $333(4.5)$ & $178(3.6)$ & \\
\hline 2 & $625(8.4)$ & $374(7.5)$ & \\
\hline 3 & $718(9.6)$ & $449(9.0)$ & \\
\hline 4 & $1665(22.4)$ & $1126(22.5)$ & \\
\hline 5 & $2471(33.2)$ & $1820(36.3)$ & \\
\hline Missing & $452(6.1)$ & $341(6.8)$ & \\
\hline Charlson comorbidity index, $n(\%)$ & & & 0.3 \\
\hline $0-1$ & $4663(62.6)$ & $3140(62.7)$ & \\
\hline $2-3$ & $2424(32.6)$ & $1624(32.4)$ & \\
\hline
\end{tabular}


Table 6 Patient characteristics in the groups with differential distance $=0 \mathrm{~km}$ or $>0 \mathrm{~km}$ (Continued)

\begin{tabular}{|c|c|c|c|}
\hline$\geq 4$ & $359(4.8)$ & $244(4.9)$ & \\
\hline Intensive care unit admission, $n(\%)$ & $668(9.0)$ & $414(8.3)$ & 2.5 \\
\hline Oxygen intake at admission, $n(\%)$ & $5238(70.3)$ & $3470(69.3)$ & 2.3 \\
\hline Intubation at admission, $n$ (\%) & $252(3.4)$ & $228(4.6)$ & 6 \\
\hline Steroid dose (mg), mean (sd) & 206 (609) & $219(643)$ & 2.2 \\
\hline Hospital volume, mean (sd) & $222(128)$ & $219(138)$ & 2.4 \\
\hline $\begin{array}{l}\text { Population density of patient living } \\
\text { area } \leq 249 \text { persons } / \mathrm{km}^{2}, n(\%)\end{array}$ & $1147(15.4)$ & $752(15.0)$ & 1.1 \\
\hline $\begin{array}{l}\text { Distance between patient residence } \\
\text { and hospital }(\mathrm{km}) \text {, mean (SD) }\end{array}$ & $6.08(14.84)$ & $8.58(36.81)$ & 8.9 \\
\hline Early pulmonary rehabilitation & $0.38(0.49)$ & $0.24(0.43)$ & 30.2 \\
\hline $\begin{array}{l}\text { Rehabilitation total session (hours), } \\
\text { mean (sd) }\end{array}$ & $8.3(12.7)$ & $7.4(11.0)$ & 7.2 \\
\hline Rehabilitation duration (days), mean (sd) & $18.2(20.0)$ & $19.2(21.5)$ & 4.8 \\
\hline
\end{tabular}

\section{Appendix 3}

Table 7 Risk-adjusted treatment effects of early pulmonary rehabilitation on the outcomes with complete case data

\begin{tabular}{lll}
\hline & Risk-adjusted treatment effect ${ }^{\mathrm{a}}$ (95\% Confidence interval) & $P$ value \\
\hline 90-day readmission (\%) & $-3.4(-5.7$ to -1.5$)$ & 0.001 \\
Barthel index $\geq 15$ at discharge (\%) & $0.18(-1.7$ to 2.2$)$ & 0.552 \\
Length of stay (days) & $-9.8(-10.8$ to -8.7$)$ & $<0.001$
\end{tabular}

${ }^{a}$ Adjusted for age, sex, pre-admission within 180 days, Japan coma scale, body mass index, smoking index, Barthel index, Hugh-Jones score, Charlson comorbidity index, intensive care unit admission, steroid dose, hospital volume, population density of patient living area, and distance between patient residence and hospital

Table 8 Two-stage least squares estimates for outcomes with complete case data, adjusted for measured and unmeasured characteristics

\begin{tabular}{|c|c|c|c|c|c|c|}
\hline & \multicolumn{2}{|l|}{ 90-day readmission } & \multicolumn{2}{|l|}{ Barthel index at discharge } & \multicolumn{2}{|c|}{ Log-transformed length of stay } \\
\hline & Coefficient $(95 \% \mathrm{Cl})$ & $P$ value & Coefficient $(95 \% \mathrm{Cl})$ & $P$ value & Coefficient (95\% Cl) & $P$ value \\
\hline Ordinary least square; & $-0.0348(-0.0561,-0.0135)$ & 0.0014 & $-0.0009(-0.0204,0.0187)$ & 0.9298 & $-0.4134(-0.4551,-0.3718)$ & $<0.0001$ \\
\hline Two-stage least square & $-0.039(-0.1867,0.1088)$ & 0.6052 & $0.0664(-0.0796,0.2125)$ & 0.3727 & $-0.9087(-1.1725,-0.6450)$ & $<0.0001$ \\
\hline F statistics & 134.8 & $<0.0001$ & 117.2 & $<0.0001$ & 134.8 & $<0.0001$ \\
\hline Hausman specification test & & 0.956 & & 0.339 & & $<0.0001$ \\
\hline
\end{tabular}

Cl Confidence interval

\section{Abbreviations}

2SLS: Two-stage least square; ADL: Activities of daily living; Cl: Confidence interval; COPD: Chronic obstructive pulmonary disease; DD: Differential distance; ICD-10: International Classification of Diseases and Related Health Problems 10th revision (ICD-10); JCS: Japan Coma Scale; LOS: Length of stay; OLS: Ordinary least square; PR: Pulmonary rehabilitation; RCT: Randomised controlled trials; SD: Standard deviation

\section{Acknowledgements}

Not applicable.

\section{Funding}

This study was funded by Grants-in-Aid for Research on Policy Planning and Evaluation (Grant Numbers: H27-Policy-Designated-009 and H27Policy-Strategy-011) from the Japanese Ministry of Health, Labour and Welfare.

\section{Availability of data and materials}

Because individual privacy could be compromised, the datasets analysed during the current study are not publicly available. But they are available from the corresponding author on reasonable request.

\section{Authors' contributions}

$\mathrm{HM}$ and $\mathrm{HY}$ contributed to the conception and design of the study. KF and HY contributed to the data collection. HM and HY contributed to the data analysis. All authors contributed to the data interpretation and drafting of the manuscript for important intellectual content. All authors read and approved the final manuscript.

\section{Competing interests}

All authors have completed declare: no support from any organisation for the submitted work; no financial relationships with any organisations that might have an interest in the submitted work in the previous 3 years; and 
no other relationships or activities that could appear to have influenced the submitted work.

\section{Consent for publication}

Not applicable.

\section{Ethics approval and consent to participate}

This study was approved by the Institutional Review Board of The University of Tokyo (Approval Number: 3501-(1)). Because all data were de-identified, the requirement for patient informed consent was waived.

\section{Publisher's Note}

Springer Nature remains neutral with regard to jurisdictional claims in published maps and institutional affiliations.

\section{Author details}

${ }^{1}$ Department of Clinical Epidemiology and Health Economics, School of Public Health, The University of Tokyo, 7-3-1 Hongo, Bunkyo-ku, Tokyo 113-0033, Japan. '2Department of Health Services Research, Graduate School of Medicine, The University of Tokyo, 7-3-1 Hongo, Bunkyo-ku, Tokyo 113-0033, Japan. ${ }^{3}$ Department of Health Policy and Informatics, Graduate School of Medicine, Tokyo Medical and Dental University, 1-5-45 Yushima, Bunkyo-ku, Tokyo 113-8510, Japan.

Received: 7 January 2017 Accepted: 12 April 2017

Published online: 21 April 2017

\section{References}

1. Pitta F, Troosters T, Probst VS, Spruit MA, Decramer M, Gosselink R. Physical activity and hospitalization for exacerbation of COPD. Chest. 2006;129:536-44

2. Spruit MA, Singh SJ, Garvey C, ZuWallack R, Nici L, Rochester C, et al. An official American Thoracic Society/European Respiratory Society statement: key concepts and advances in pulmonary rehabilitation. Am J Respir Crit Care Med. 2013;188:e13-64.

3. Garcia-Aymerich J, Farrero E, Felez MA, Izquierdo J, Marrades RM, Anto JM. Risk factors of readmission to hospital for a COPD exacerbation: a prospective study. Thorax. 2003;58:100-5.

4. Puhan MA, Gimeno-Santos E, Scharplatz M, Troosters T, Walters EH, Steurer J. Pulmonary rehabilitation following exacerbations of chronic obstructive pulmonary disease. Cochrane Database Syst Rev. 2011;10:CD005305.

5. Ko FW, Dai DL, Ngai J, Tung A, Ng S, Lai K, et al. Effect of early pulmonary rehabilitation on health care utilization and health status in patients hospitalized with acute exacerbations of COPD. Respirology. 2011;16:617-24.

6. Greening NJ, Williams JE, Hussain SF, Harvey-Dunstan TC, Bankart MJ, Chaplin EJ, et al. An early rehabilitation intervention to enhance recovery during hospital admission for an exacerbation of chronic respiratory disease: randomised controlled trial. BMJ. 2014;349:g4315.

7. Yamana $H$, Horiguchi $H$, Fushimi K, Yasunaga $H$. Comparison of procedurebased and diagnosis-based identifications of severe sepsis and disseminated intravascular coagulation in administrative data. J Epidemiol. 2016;26:530-7.

8. Hugh-Jones P, Lambert AV. A simple standard exercise test and its use for measuring exertion dyspnoea. Br Med J. 1952;1:65-71.

9. Shigematsu K, Nakano H, Watanabe $\mathrm{Y}$. The eye response test alone is sufficient to predict stroke outcome-reintroduction of Japan Coma Scale: a cohort study. BMJ Open. 2013. doi:10.1136/bmjopen-2013-002736.

10. Mahoney Fl, Barthel DW. Functional evaluation: the Barthel index. Md State Med J. 1965;14:61-5.

11. Momosaki $R$, Yasunaga $H$, Matsui $H$, Horiguchi $H$, Fushimi $K$, Abo M. Effect of early rehabilitation by physical therapists on in-hospital mortality after aspiration pneumonia in the elderly. Arch Phys Med Rehabil. 2015;96:205-9.

12. Hasegawa W, Yamauchi $Y$, Yasunaga $H$, Sunohara M, Jo T, Matsui $H$, et al. Factors affecting mortality following emergency admission for chronic obstructive pulmonary disease. BMC Pulm Med. 2014;14:151.

13. Quan H, Li B, Couris CM, Fushimi K, Graham P, Hider P, Januel JM, et al. Updating and validating the Charlson comorbidity index and score for risk adjustment in hospital discharge abstracts using data from 6 countries. Am J Epidemiol. 2011;173:676-82.

14. Yamauchi $Y$, Yasunaga $H$, Matsui $H$, Hasegawa W, Jo T, Takami $K$, et al. Comparison of in-hospital mortality in patients with COPD, asthma and asthma-COPD overlap exacerbations. Respirology. 2015;20:940-6.
15. Yamauchi Y, Hasegawa W, Yasunaga H, Sunohara M, Jo T, Takami K, et al. Paradoxical association between body mass index and in-hospital mortality in elderly patients with chronic obstructive pulmonary disease in Japan. Int J Chron Obstruct Pulmon Dis. 2014:9:1337-46.

16. Dres M, Tran TC, Aegerter P, Rabbat A, Guidet B, Huchon G, et al. Influence of ICU case-volume on the management and hospital outcomes of acute exacerbations of chronic obstructive pulmonary disease. Crit Care Med. 2013;41:1884-92.

17. Austin PC. An introduction to propensity score methods for reducing the effects of confounding in observational studies. Multivariate Behav Res. 2011:46:399-424.

18. Austin PC. Balance diagnostics for comparing the distribution of baseline covariates between treatment groups in propensity-score matched samples. Stat Med. 2009;28:3083-107.

19. Williams R. Using the margins command to estimate and interpret adjusted predictions and marginal effects. Stata J. 2012;12:308-31.

20. Wooldridge JM. Econometric analysis of cross section and panel data. 2nd ed. Cambridge: MIT Press; 2010.

21. Sanchez G. How do I obtain bootstrapped standard errors with panel data? Stata. 2011. http://www.stata.com/support/faqs/statistics/bootstrap-withpanel-data/. Accessed 4 Oct 2016.

22. Angrist JD, Pischke J-S. Mostly harmless econometrics : an empiricists companion. Princeton, NJ: Princeton University Press; 2013.

23. Brookhart MA, Rassen JA, Schneeweiss S. Instrumental variable methods in comparative safety and effectiveness research. Pharmacoepidemiol Drug Saf. 2010:19:537-54.

24. McClellan M, McNeil BJ, Newhouse JP. Does more intensive treatment of acute myocardial infarction in the elderly reduce mortality? Analysis using instrumental variables. JAMA. 1994;272:859-66.

25. Newhouse JP, McClellan M. Econometrics in outcomes research: the use of instrumental variables. Annu Rev Public Health. 1998;19:17-34.

26. Buuren S. Groothuis-Oudshoorn K: mice: multivariate imputation by chained equations in R. J Stat Software. 2011:45.

27. Rubin DB. Multiple imputation after 18+ years. J Am Stat Assoc 1996;91:473-89.

28. Licht C. New methods for generating significance levels from multiplyimputed data. 2010. Bamberg, https://opus4.kobv.de/opus4-bamberg/ frontdoor/index/index/docld/270. Accessed 1 Nov 2016.

29. Kirsten DK, Taube C, Lehnigk B, Jorres RA, Magnussen H. Exercise training improves recovery in patients with COPD after an acute exacerbation. Respir Med. 1998;92:1191-8.

30. Seymour JM, Moore L, Jolley CJ, Ward K, Creasey J, et al. Outpatient pulmonary rehabilitation following acute exacerbations of COPD. Thorax. 2010;65:423-8.

31. Maddocks M, Kon SS, Singh SJ, Man WD. Rehabilitation following hospitalization in patients with COPD: can it reduce readmissions? Respirology. 2015;20:395-404.

32. Man WD, Kon SS, Maddocks M. Rehabilitation after an exacerbation of chronic respiratory disease. BMJ. 2014;349:94370.

33. Vitacca M, Paneroni M, Baiardi P, De Carolis V, Zampogna E, Belli S, et al. Development of a Barthel Index based on dyspnea for patients with respiratory diseases. Int J Chron Obstruct Pulmon Dis. 2016;11:1199-206.

\section{Submit your next manuscript to BioMed Central and we will help you at every step:}

- We accept pre-submission inquiries

- Our selector tool helps you to find the most relevant journal

- We provide round the clock customer support

- Convenient online submission

- Thorough peer review

- Inclusion in PubMed and all major indexing services

- Maximum visibility for your research

Submit your manuscript at www.biomedcentral.com/submit 